\title{
A Deficiência Auditiva e a possibilidade de Inclusão no Mercado de Trabalho
}

\author{
Geovane Rodrigues de Freitas $^{1}$; Thércia Lucena Grangeiro Maranhão ${ }^{2}$; Waleska Maria Félix ${ }^{3}$
}

Resumo: As pessoas com deficiência auditiva, por meio de conquistas legais, obtiveram a sua inserção no mercado de trabalho. No entanto, isso não garante de fato uma inclusão social, pois esta depende do emprego da língua de sinais e do reconhecimento dos reais desafios, necessidades e potencialidades dessas pessoas. Assim a presente pesquisa busca retratar a relação do deficiente auditivo com o mercado de trabalho, enfatizando a sua inclusão dentro da instituição contratadora bem como a sua interação com os funcionarios não deficientes aparti da utilização da LIBRAS. Foi utilizado o metodo qualitativo, fundamentado na aplicação de entrevistas, possibilitando uma melhor compreenção do tema proposto. Após a interpretação dos dados obtidos, foi possivel identificar que embora a pessoa com deficiencia já esteja inserida no mercado de trabalho da região do cariri, ainda há muito pra evoluir, principalmente no que tange a utilização da LIBRAS como ferramenta de inclusão.

Palavras - Chaves: Inclusão, Deficientes Auditivos, Mercado de Trabalho.

\section{Auditory Disorder and the Inclusion Possibility In the Labor Market}

\begin{abstract}
People with hearing impairment, through legal achievements, obtained their integration into the labor market. However, this does not guarantee indeed a social inclusion, as this depends on the use of sign language and the recognition of the real challenges, needs and potential of disabled persons. Thus the present research seeks to portray the relationship of the hearing impaired to the labor market, emphasizing its inclusion within the contratadora institution as well as its interaction with non-disabled employees aparti the use of LIBRAS. It used the qualitative method, based on the application of interviews, enabling a better comprehension of the proposed theme. After the interpretation of data obtained through the interviews, it was possible to identify that while the disabled person is already inserted in the cariri region labor market, there is still a lot to evolve, especially regarding the use of LIBRAS as inclusion tool.
\end{abstract}

Key Words: Inclusion, Deaf, Labour Market.

\section{Introdução}

O interesse na elaboração desse trabalho surge com o desejo de conhecer e compreender a realidade vivenciada pelas pessoas com deficiência auditiva, inseridas no mercado de trabalho na região do Cariri.

\footnotetext{
${ }^{1}$ Graduando do curso Psicologia do Centro Universitário Doutor Leão Sampaio - UNILEÃO - Email: geovanerodrigues93@ hotmail.com

${ }^{2}$ Psicologa. Professora do Centro Universitário Doutor Leão Sampaio - UNILEÃO. Email: thercia@ leaosamapio.edu.br

${ }^{3}$ Graduação em Enfermagem pela Faculdade de Juazeiro do Norte - FJN.
} 
Verificando o contexto historico das pessoas com deficiência auditiva, procuramos conhecer melhor a aceitação destas no mercado de trabalho, na intenção de retratar que pessoas com deficiência auditiva tem habilidades, podendo fazer parte do mercado de trabalho e da sociedade. Assim, procura-se verificar se destinadas vagas para as pessoas com deficiência auditiva no mercado, a respeito do preconceito, e se o ambiente de trabalho é adequado para aos mesmos (TELES, 2011).

A expressão "pessoa surda" tem procurado abrir um espaço social para as pessoas com deficiência auditiva, respeitando suas especificidades e buscando sua identidade social e legitimação como comunidade linguística diferenciada. Ela acaba expressando a tentativa de suavizar determinadas condições dos sujeitos, desnudando um preconceito interiorizado. Por acreditarmos que são expressões aceitas, coerentes e de caráter não discriminatório, optamos por usar, neste trabalho, as expressões pessoa com deficiência auditiva (PINTO et al, 2009).

Apartir das discussões acima atreladas e a curiosidade sobre o tema levanta-se a seguinte questão: existem "vagas" para os deficientes auditivos e de que forma ocorre a inclusão e valorização destes no mercados de trabalho na região do Cariri.

As questões norteadoras da pesquisa levam em conta um conjunto de condicionalidades que elucidam a relação entre os deficintes auditivos e o mercado de trabalho, como: tratamento diferenciado por parte das empresas, após sua inserção; falta de interação entre as pessoas (colegas de trabalho); desconhecimento da LIBRAS por parte dos funcionários; ausência de intérpretes da LIBRAS para viabilizar a interlocução e comunicação no ambiente gerando a exclusão.

Assim, a presente pesquisa tem como objetivo principal retratar a relação do deficiente auditivo com o mercado de trabalho na região do Cariri, tendo como objetivos especificos analisar o processo de inclusão deste funcionário com deficiência auditiva dentro da instituição contratadora, sua interação com os funcionarios não deficientes, bem como, a utilizição da LIBRAS como ferramenta de interração.

A pessoa com deficiência inserida no mercado de trabalho, na maioria das vezes, está sujeita à discriminação, pelo fato de ter deficiência, por não ter qualificação ou por não se enquadrar nos "padrões ditos normais" da sociedade. A inclusão no mercado de trabalho proporciona ao surdo sua valorização como cidadão, leva à efetivação dos seus direitos 
Id on Line Revista Multidisciplinar e de Psicologia

Id on Line Multidisciplinary and Psycology Journal

garantidos em lei, e possibilita a convivência no ambiente de trabalho com trabalhadores ouvintes e, consequentemente, maior sociabilidade (PINTO et al, 2009).

Ao incorporarem pessoas com deficiência no seu quadro de funcionários, as empresas obtêm reconhecimento social, pois atraves das relações de trabalho consideradas inclusivas, projeta-se uma imagem positiva na sociedade empresarial. Assim, a inclusão da pessoa com deficiência auditiva pode possibilitar às empresas serem compreendidas de modo diferente (PAIVA et al, 2013).

A comunicação humana é de fundamental importância para a constituição de um meio social saudável. O principal meio de comunicação entre as pessoas é sem dúvida a fala. No entanto, alguns fatores podem acarretar prejuízo na sua produção. Dentre eles, estão as perdas de audição. Indivíduos, que, por alguma razão perderam a audição e apresentam apenas restos auditivos, enfrentam dificuldades para se comunicar oralmente. Sabemos que a falta de feedback auditivo é responsável pelas alterações na qualidade vocal e na produção da fala de indivíduos surdos. A relação entre a articulação e a qualidade vocal nos deficientes auditivos é essencial para garantir a inteligibilidade de fala (DIAZ et al, 2009).

Para identificação da problematica proposta pela pesquisa, foi utilizado o metodo qualitativo, fundamentado na aplicação de entrevistas semi estruturadas, possibilitando uma melhor compreensão do tema proposto. Após a interpretação dos dados, foi possivel identificar que, embora a pessoa com deficiencia já esteja inserida no mercado de trabalho da região do Cariri, o processo de inclusão ainda ocorre de forma insastifastoria. E importante salientar que ainda há muito a evoluir, principalmente no que tange a utilização da LIBRAS como ferramenta de inclusão.

\section{Pessoas com Deficiência}

No censo do IBGE de 2010, mais de 45,6 milhões de Brasileiros declararam ter algum tipo de deficiência. Este número representa 23,9\% da população do país. Deste total cerca de 9,7 milhões, possuem algum tipo de deficiência auditiva. O Ceará soma pelo menos 2.340.150 pessoas com deficiência. Segundo um estudo divulgado pelo IPECE, que compilou os dados 
estadual e regional, o Ceará possui hoje cerca de 526 mil pessoas com algum tipo de deficiência auditiva. E importante salientar que dos cerca de 45,6 milhões de brasileiros com deficiência, 18,9 milhões estão em idade de trabalhar. Em 2010, 17,4 mil novos empregos formais foram ocupados por pessoas com deficiência. Com o acréscimo, chega-se ao estoque de 306 mil trabalhadores com deficiência em atividade no Brasil, crescimento de 6,2\% em relação a 2009 (288,6 mil) (IBGE, 2010). Abaixo segue Gráfico 01 com mais informações:

\section{Tipo de Deficiencia}

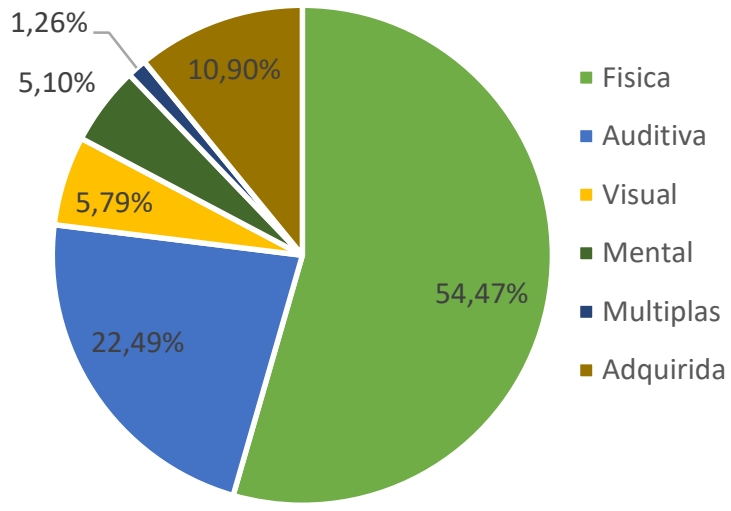

Grafico 01: Tipos de Deficiencia

Fonte: RAIS 2010

Como demonstrado acima, verifica-se a predominância dos trabalhadores classificados com deficiência física, seguida dos auditivos e visuais. Quanto ao gênero desses trabalhadores, os homens têm uma maior representatividade em todos os tipos de deficiência. Quando analisamos apenas os dados de deficiência auditiva, no que tange a nível de escolaridade, o público pesquisado apresenta um grau de qualificação considerado elevado (Gráfico 02). A maior parcela das pessoas declarou que possui ensino médio completo. Porém 61,5\% possuem grau de qualificação a partir de ensino superior chegando até pós-graduação. Apenas a minoria declarou possuir apenas o ensino fundamental (RAIS, 2010). 


\section{Escolaridade}

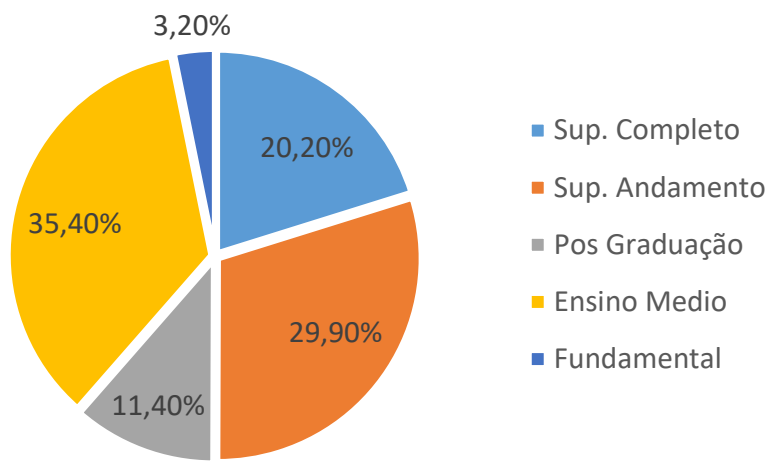

Grafico 02: Nivel de Escolaridade

Fonte: RAIS 2010

Com base nestas informações supõe-se que os respondentes são pessoas instruídas com alto grau de acesso à informação. São pessoas que trazem opiniões valiosas sobre o panorama do mercado de trabalho para pessoas com deficiência. Os dados deste gráfico auxiliam também na derrubada de um dos maiores mitos difundido por aqueles que trabalham na contramão da inclusão: "as pessoas com deficiência não são qualificadas”. Certamente que a grande parte da população com deficiência é pouco qualificada, assim como a grande parte da população brasileira. Entretanto, a afirmação anterior generaliza o grupo de pessoas com deficiência, incluindo-os em uma única categoria, a dos não qualificados (RAIS, 2010).

\section{Deficiencia Auditiva}

Deficiência auditiva é o nome usado para indicar perda de audição ou diminuição na capacidade de escutar os sons. Qualquer problema que ocorra em alguma das partes do ouvido pode levar a uma deficiência na audição (CORREIA, 2009).

Considera-se, em geral, que a audição normal corresponde à habilidade para detecção de sons até 20 dBN.A (decibéis, nível de audição). Como voz e audição são aspectos que se relacionam e ouvir é uma atividade complexa e elaborada, que envolve desde a detecção de 
Id on Line Revista Multidisciplinar e de Psicologia

Id on Line Multidisciplinary and Psycology Journal

estímulos sonoros pelos órgãos periféricos até sua interpretação pelo sistema auditivo nervoso central, pode-se dizer que a audição configura um fator importante para a manutenção de um padrão vocal adequado (DIAZ et al, 2009). Abaixo mostraremos os diferentes tipos de deficiencia auditiva:

$\checkmark$ Condutiva: qualquer interferência na transmissão do som desde o conduto auditivo externo até a orelha interna (cóclea). A orelha interna tem capacidade de funcionamento normal mas não é estimulada pela vibração sonora. Esta estimulação poderá ocorrer com o aumento da intensidade do estímulo sonoro. A grande maioria das deficiências auditivas condutivas pode ser corrigida através de tratamento clínico ou cirúrgico.

$\checkmark$ Sensório-neural: ocorre quando há uma impossibilidade de recepção do som por lesão das células ciliadas da cóclea ou do nervo auditivo. Os limiares por condução óssea e por condução aérea, alterados, são aproximadamente iguais. A diferenciação entre as lesões das células ciliadas da cóclea e do nervo auditivo só pode ser feita através de métodos especiais de avaliação auditiva. Este tipo de deficiência auditiva é irreversível.

$\checkmark$ Mista: ocorre quando há uma alteração na condução do som até o órgão terminal sensorial associada à lesão do órgão sensorial ou do nervo auditivo. $\mathrm{O}$ audiograma mostra geralmente limiares de condução óssea abaixo dos níveis normais, embora com comprometimento menos intenso do que nos limiares de condução aérea.

$\checkmark$ Disfunção auditiva central ou surdez central: este tipo de deficiência auditiva não é, necessariamente, acompanhado de diminuição da sensitividade auditiva, mas manifesta-se por diferentes graus de dificuldade na compreensão das informações sonoras. Decorre de alterações nos mecanismos de processamento da informação sonora no tronco cerebral (sistema nervoso central).

Com base nas informações citadas acima, alguns autores listam os seguintes agentes como fatores de risco que podem causar deficiência auditiva (DIAZ et al, 2009):

$\checkmark$ Histórico Familiar, levantando-se se há consanguinidade entre os pais e/ou hereditariedade.

$\checkmark$ Infecções congênitas (toxoplasmose, rubéola, citomegalovírus, herpes e sífilis).

$\checkmark$ Peso no nascimento inferior a $1500 \mathrm{~g}$ e/ou crianças pequenas para a idade gestacional (PIG). 
$\checkmark$ Asfixia severa no nascimento, com apagar entre 0-4 no primeiro minuto e $0-6$ no quinto minuto.

$\checkmark$ Hiperbilirrubinemia com índices que indiquem exanguíneo transfusão.

$\checkmark$ Ventilação mecânica por mais de dez dias.

$\checkmark$ Alterações crânio-faciais, incluindo as síndromes que tenham como uma de suas características a deficiência auditiva.

$\checkmark$ Meningite, principalmente a bacteriana.

$\checkmark$ Uso de drogas ototóxicas por mais de cinco dias.

$\checkmark$ Permanência em incubadora por mais de sete dias.

$\checkmark$ Alcoolismo ou uso de drogas pelos pais, antes e durante a gestação.

\section{Deficientes Auditivos na Região Metropolitana do Cariri}

A região metropolitana do Cariri surgiu a partir da cornurbação entre os municípios de Juazeiro do Norte, Crato e Barbalha, (chamada triângulo caririese "CRAJUBAR"). Foi criada pela Lei Complementar Estadual $\mathrm{n}^{\mathrm{o}} 78$ sancionada em 29 de junho de 2009. Sendo composta pelos municias sobreditos, acrescidos do demais municípios Caririaçu, Farias Brito, Jardim, Missão Velha, Nova Olinda e Santana do Cariri (Figura 01). Com área superior a $5400 \mathrm{Km}^{2}$, com uma população de 590209 mil habitantes. Tem como área de influência a região sul do Ceará e a região da divisa entre o Ceará e os estados de Pernambuco, Paraíba e Piauí. (IBGE, 2010). 


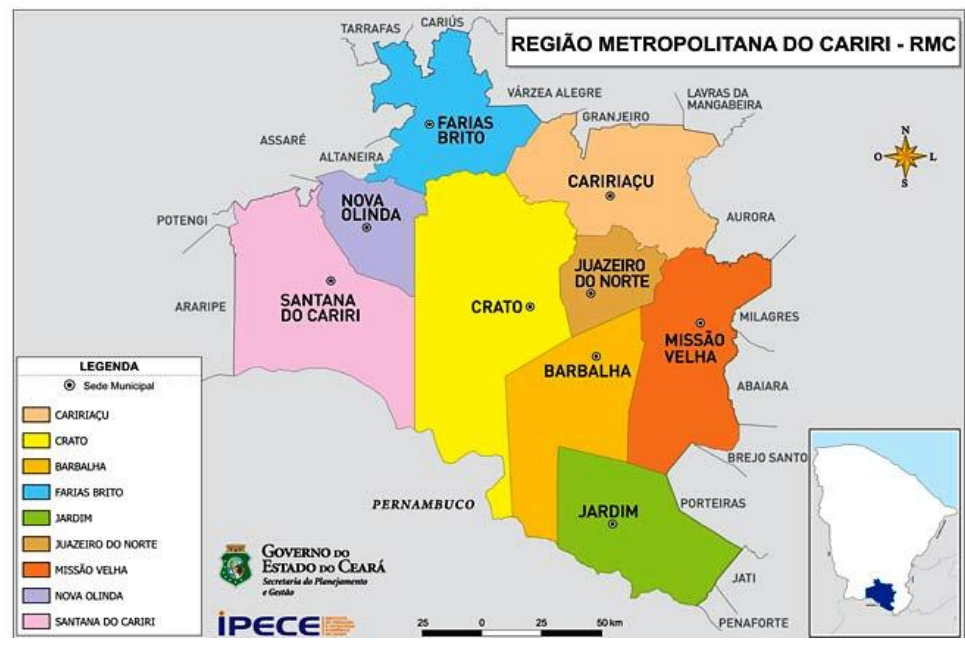

Figura 01: Mapa Região Metropolitana do Cariri

Fonte: IPECE

Segundo dados do IBGE (CENSO 2010), na Região do Cariri cearense há mais de 30 mil pessoas com deficiência auditiva. Apenas em Juazeiro do Norte são mais de 14 mil surdos. Apesar de apresentar uma quantidade tão elevada de pessoas com deficiência auditiva, as primeiras atividades relacionas ao ensino de LIBRAS na região do Cariri, tiveram início em meados de 2005. As atividades relacionadas ao ensino de LIBRAS, foram iniciadas aparti da instalação do INTRA (Instituto Transformar) na cidade Juazeiro do Norte. Esta ONG foi responsável pelo pontapé inicial, mas hoje em nossa região contamos com uma serie de instituições, realizando cursos de LIBRAS.

A cidade de Juazeiro do Norte vem se destacando no cenario regional. No ano de 2010, foi criada a lei Lei $\mathrm{N}^{\mathrm{o}}$ 3656, "Institui a obrigatoriedade da inclusão da Língua Brasileira de Sinais - LIBRAS - no currículo escolar no âmbito do Município de Juazeiro do Norte." No ano de 2011 foi fundada a Associação dos Profissionais Tradutores/Intérpretes de Língua Brasileira de Sinais da Região Metropolitana do Cariri (APILMSC), que embora esteja sediada em Juazeiro do Norte, atua nas demais cidades da região. E no início de 2014, foi criada atraves da parceria entre os governos federal e estadual a Central de Interpretação de LIBRAS, contando inicialmente com 13 interpretes, atuando principalmente no triangulo CRAJUBAR. 
Id on Line Revista Multidisciplinar e de Psicologia

Id on Line Multidisciplinary and Psycology Journal

\title{
Inclusão Social
}

Ao propor este tema, é preciso deixar claro que o percurso histórico no qual, gradativamente, pessoas com limitações físicas, sensoriais ou cognitivas foram incorporadas ao tecido e estrutura social é um processo errático, não-linear e marcado, invariavelmente, por trajetórias individuais. Não se pode visualizar um movimento contínuo e homogêneo de integração, pois os sentimentos e a maneira pela qual a sociedade enxergava as pessoas com deficiência variavam também de um país para outro num mesmo período historico. Durante o século XX, por exemplo, pessoas com deficiência foram submetidas a "experiências científicas" na Alemanha nazista de Hitler. Ao mesmo tempo, mutilados de guerra eram considerados heróis em países como os EUA, recebendo honrarias e tratamento em instituições do governo (SILVA, 1987).

O conceito de inclusão não nega o conceito de desigualdade, na verdade defende o convívio dos desiguais de maneira igualitária. É por existirem as desigualdades que o ser humano busca o convívio com iguais e procura se associar a vários grupos. (BATISTA, 2000)

Por sua vez, Sassaki (1997) menciona que “a inclusão é o processo pelo qual a sociedade se adapta para poder incluir em seus sistemas sociais gerais, pessoas com deficiência e, simultaneamente estas se preparam para assumir seus papéis na sociedade."

De acordo com Batista (2004, p. 23),

\begin{abstract}
A inclusão social é geralmente almejada não só pelas pessoas com deficiência, mas por todo indivíduo que se sente excluído, de alguma forma, do convívio social. Os parâmetros para definir o que seja essa inclusão social são vagos ou de difícil quantificação, mas parece evidente que a inclusão social significa mais do que a mera sobrevivência.
\end{abstract}

Assim, a inclusão social das pessoas com deficiências significa torná-las participantes da vida social, económica e política, assegurando o respeito aos seus direitos no âmbito da sociedade, do Estado e do Poder Público. A inclusão é um processo que acontece gradualmente, com avanços e retrocessos isto porque os seres humanos são de natureza complexa e com heranças antigas, têm preconceitos e diversas maneiras de entender o mundo. Assim sendo, 
Id on Line Revista Multidisciplinar e de Psicologia

Id on Line Multidisciplinary and Psycology Journal

torna-se difícil terminar com a exclusão e mesmo existindo leis contra a mesma, não são leis que vão mudar, de um dia para o outro, a mentalidade da sociedade assim como o seu preconceito (PINTO et al, 2009).

As sociedades antepassadas não aceitavam a deficiência, provocando uma exclusão quase total das pessoas portadoras desta. As famílias chegavam mesmo a escondê-las da convivência com outros, isolando-as do mundo. Felizmente, o mundo desenvolveu-se levando a uma maior aceitação da deficiência devido ao aparecimento de novos pensamentos e mentalidades. Estas transformações aconteceram, em grande maioria, no final do século XIX, e começo do século XX na Revolução Industrial, com o aparecimento do interesse pela educação nos países desenvolvidos (SILVA, 1987).

O termo inclusão, tem sido em muitos casos, compreendido de forma equivocada, pois na maioria das vezes é adotado do ponto de vista social como sendo apenas incluir, colocar junto com outros e ponto final. Entretanto, a inclusão é antes de tudo um processo de se autoanalisar, de procurar no outro o que ele tem a nos oferecer, de perceber a forma como vê a vida, as coisas e as pessoas. Portanto, fica patente que a inclusão social engloba a aceitação das diferenças individuais e à valorização de cada pessoa na convivência dentro da diversidade humana (PAIVA et al, 2013).

De acordo com Batista (2004), “a integração social nem sempre proporciona à pessoa com deficiência garantia de inclusão, pois, muitas vezes, existe uma relação baseada na tolerância." Apesar de estarem inseridos no meio social, podendo compartilhar de um mesmo ambiente que as demais pessoas, e sofrer algum tipo de segregação.

\section{Inclusão Social de Deficientes Auditivos}

No decorrer da história, a surdez foi alvo de incompreensão, apresentada apenas por aspectos negativos onde os surdos foram estigmatizados de várias formas, desde loucos, doentes até como pessoas castigadas pelos deuses (SILVA, 1987).

O processo de Inclusão Social deve ter início na escola, uma vez que a escola é o ambiente social no qual o indivíduo tem o primeiro contato externo ao seio familiar, onde ele aprende a se relacionar com as pessoas e com diferentes situações. Conforme Carvalho, a escola 
Id on Line Revista Multidisciplinar e de Psicologia

Id on Line Multidisciplinary and Psycology Journal

é muito importante na formação do sujeito em todos os aspectos. É um lugar de aprendizagem de diferenças e de trocas de conhecimentos, precisando, portanto atender a todos sem distinção, a fim de não promover fracassos, discriminações e exclusões (MAZZOTTA, 2013).

Em 1857 foi fundada a primeira escola para surdos no Brasil, sob a lei 939 o Instituto dos Surdos-mudos, hoje Instituto Nacional da Educação de Surdos (INES). Foi a partir deste instituto que surgiu a Língua Brasileira de Sinais, LIBRAS (DINIZ, 2010).

A inclusão do aluno surdo no ensino regular é determinante para o seu desenvolvimento enquanto participa de um contexto sociocultural, pois valida o comprometimento do real propósito escolar. Sabe-se que o aspecto fundamental para o desenvolvimento do homem, principalmente quando reporta déficits como o caso em estudo, já que implica grandes dificuldades de interação devido o comprometimento da perda auditiva, pois esta acarreta pouca ou nenhuma socialização com as pessoas ouvintes e, portanto, necessitam de intervenções pedagógicas, familiares e sociais para ser agradável, necessária e socializadora, sua participação com o mundo que o cerca (DA SILVA FÉLIX, 2010).

Sob este panorama configura-se o espaço da sala de aula. Este espaço em que atualmente as atenções estão voltadas para questões de acessibilidade a todos e permanência, tem a responsabilidade de não trabalhar apenas com o modelo ideal de aluno quieto, passivo e de "aspecto saudável”, mas também com aqueles que não seguem esta linearidade de aluno ideal, ou seja, alunos provindos de diferenças étnicas, sociais, físicas, sexuais e intelectuais. Porém é preciso esclarecer que não é somente o ambiente escolar que não está familiarizado com esta descontinuidade de perfil do ser humano, mas a sociedade como um todo.

\section{Mercado de Trabalho}

De acordo com o art. 3 da Constituição Federal, todos temos o direito de ir e vir, de trabalhar e de estudar sendo estes a mola mestra da inclusão de qualquer cidadão e, para que se concretize em face das pessoas com deficiência, há que se exigir do Estado a construção de uma sociedade livre, justa e solidária, por meio da implantação de políticas públicas compensatórias e eficazes (BRASIL, 1988). 
Id on Line Revista Multidisciplinar e de Psicologia

Id on Line Multidisciplinary and Psycology Journal

Segundo Sassaki (2006), pode-se verificar as fases de evolução dos procedimentos de profissionalização do portador de deficiência adotados pela sociedade:

$\checkmark$ Fase de exclusão: negação do trabalho ao portador de deficiência. O trabalho da pessoa com deficiência é visto como forma de exploração e crueldade.

$\checkmark$ Fase de segregação: parcerias entre instituições educacionais e empresas, pessoa com deficiência trabalha no seu domicílio ou em oficinas protegidas

$\checkmark$ Fase de integração: pessoa com deficiência é inserida no mercado de trabalho, mas não são feitos ajustes no espaço de trabalho ou na cultura predominante; ou são feitos pequenos ajustes; ou o espaço de trabalho é segregativo.

$\checkmark$ Fase de inclusão: é promovida a profissionalização da pessoa com deficiência via instituições especializadas, centros de reabilitação e associações de pessoas deficientes. As modalidades de profissionalização oferecidas vão desde o treinamento para colocação em emprego competitivo até o programa de emprego apoiado, passando por alternativas como o trabalho protegido (oficinas) ou programas de pré-profissionalização. Ou seja, todos os envolvidos fazem adaptações: as instituições de ensino, de seu currículo; as empresas, de seus processos, estrutura e cultura; e a pessoa com deficiência, assumindo a postura de participante crítico e ativo em seu processo de inclusão.

Com base nas definições propostas acima, percebe-se que na sociedade brasileira houve uma transição do modelo de integração para o de inclusão. Apresentadas as diferentes percepções sobre a deficiência ao longo da história, vejamos a seguir a definição correntemente utilizada (SASSAKI, 2006).

A primeira barreira que o indivíduo surdo encontra é a comunicação, que configura uma situação de restrição que pode desencadear conflitos no contato social. As empresas, por sua vez, devem primar pelo respeito ao princípio constitucional do valor social do trabalho e da livre iniciativa, para que se implementem a cidadania plena e a dignidade do trabalhador com ou sem deficiência e o que diz o art. $1^{\circ}$ e $170^{\circ}$ da Constituição Federal (BRASIL, 1988).

O preconceito é muito comum no mundo, e se tratando das pessoas com surdez geralmente a sociedade os vê como loucos, referindo-se como doidos. Os surdos são capazes de trabalhar e viver da mesma forma que os ouvintes, mais ainda existem o preconceito quanto a isto. Percebe-se que existe uma cultura na sociedade que considera toda pessoa surda como 
Id on Line Revista Multidisciplinar e de Psicologia

Id on Line Multidisciplinary and Psycology Journal

sendo também muda, e são chamados de surdo-mudo. Sabemos, porém, que existem surdos que são oralizados, conseguem verbalizar palavras, mesmos que não seja como os ouvintes, mais falam alguma coisa e que dar para entender muito bem e alguns sabem também fazer a leitura labial, ou seja, compreendem o que o outro está falando a partir do movimento dos lábios (SILVEIRA, 2009).

A denominação surdo-mudo é a mais antiga e incorreta denominação atribuída ao surdo, e infelizmente ainda utilizada em certas áreas e divulgada nos meios de comunicação. Para eles o fato de uma pessoa ser surda não significa que ela seja muda. Outro motivo de preconceito é pensar que eles são coitadinhos e ter pena por ser surdo, isso deve deixá-los constrangido, são pessoas como todas as outras. Muitas vezes agimos com preconceito e não notamos, quando paramos para pensar já cometemos o erro, tentamos voltar atrás e muitas vezes já é tarde (FENEIS, 2015).

Nota-se que a quantidade de surdos hoje está crescendo, são poucos os que têm uma função no mercado de trabalho, oportunidade para desenvolver suas habilidades, ainda há muito o que se fazer para que as pessoas com surdez tenham espaço e oportunidade no mercado de trabalho (TELES, 2011).

Nessa perspectiva, a contratação de pessoas com deficiência deve ser vista como qualquer outra, eis que se espera do trabalhador nessas condições profissionalismo, dedicação, assiduidade, enfim, atributos de qualquer empregado. Não se quer assistencialismo, e sim oportunidades. O fato de a Constituição Federal afirmar de que todos são iguais perante a lei não é excludente da medida afirmativa de que se cuida. Trata-se de materializar a igualdade real entre as pessoas a partir do pensamento de que a verdadeira igualdade consiste em se tratar igualmente os iguais e desigualmente os desiguais, na justa medida da desigualdade (PAIVA et al, 2013.

As empresas devem, assim, cumprir a lei em questão, esforçando-se para implantar programas de formação profissional, flexibilizando as exigências genéricas para a composição de seus quadros, de modo a, objetivamente, abrir suas portas a esse grupo social em evidente estado de vulnerabilidade. Trata-se de implementar uma iniciativa de combinação de esforços entre o Estado e a sociedade civil (DOS SANTOS, 2014). 
Com o atual nível de desenvolvimento de nosso pais, muitos obstáculos têm sido superados no que tange a necessidade de inserir as pessoas com deficiência no quadro funcional das instituições. Os conceitos de deficiência estão sendo revistos e a inserção das pessoas com deficiências no mercado de trabalho paasou a fazer parte do processo de inclusão social, visto que este é um direito de todos garantido pela nossa constituição. E importante que os mais diferentes setores da sociedade se mobilizarem por esta causa, afinal o envolvimento de entidades públicas e particulares se torna necessário para que o resultado seja ainda mais significativo.

\section{Deficiêntes Auditivo no Mercado de Trabalho}

Apesar das empresas contratarem trabalhadores com surdez, porem em geral elas não confiam nos mesmos para ocupar cargos mais elevado julgando a falta de comunicação com os ouvintes como impedimento. Para as empresas uma pessoa surda ocupando um cargo de chefia, representa um alto custo, pois este necessita de um interprete sempre ao lado, o que significa contratação de mais funcionários. Em uma empresa que se trabalha com maquinas, que fez barulhos eles dizem que o surdo corre riscos de acidente, e que não são capazes de produzir igual ao ouvinte (DOS SANTOS, 2014).

Quanto à inclusão no mercado de trabalho, se faz necessário assegurar condições de interação das pessoas com deficiência com os demais funcionários da empresa e com todos os parceiros e clientes com os quais lhes caiba manter relacionamento. Não se trata, portanto, somente de contratar pessoas com deficiência, mas também de oferecer as possibilidades para que estes possam desenvolver seus talentos e permanecer na empresa, atendendo aos critérios de desempenho previamente estabelecidos. (GIL, 2002). A integração profissional está ocorrendo sob três formas:

$\checkmark$ As pessoas deficientes são admitidas e contratadas em órgãos públicos e empresas particulares, desde que tenham qualificação profissional e consigam utilizar os espaços físicos e os equipamentos de trabalho sem nenhuma modificação. 
Id on Line Revista Multidisciplinar e de Psicologia

Id on Line Multidisciplinary and Psycology Journal

$\checkmark$ Pessoas deficientes são admitidas por empregadores que concordam em fazer pequenas adaptações específicas para elas, por motivos práticos e não pela causa da igualdade de oportunidades;

$\checkmark$ Pessoas deficientes são aceitas para trabalhar em empresas que as deixam trabalhando em grupos longe dos demais funcionários e do público, geralmente, sem carteira assinada e/ou, se contratadas, sem promoções ao longo dos anos.

No passado, os indivíduos que apresentavam deficiências auditivas tinham grande dificuldade para ingressar no mercado de trabalho. Isso era conseqüência da falta de preparo tanto das empresas quanto dos surdos (SASSAKI, 1997). Atualmente, uma visão mais integrada em relação ao deficiente auditivo tem substituído os velhos discursos que enfocavam somente aspectos patológicos (KLEIN, 1998).

A integração do surdo, no mercado de trabalho permite, que ele adquira sua independência econômica, sinta-se produtivo dentro do ambiente social em que vive, desejo comum a toda e qualquer pessoa.

O Brasil é um dos países mais avançados do mundo na criação de leis de proteção à pessoa portadora de deficiência. A lei que obriga empresas privadas a contratar deficientes auditivos é a mais conhecida. Trata-se da Lei n. ${ }^{\circ}$ 8.123, de 25 de julho de 1991, também conhecida como Lei de reserva de mercado, em que consta: Art. 93 - A empresa com 100 (cem) ou mais empregados está obrigada a preencher de $2 \%$ (dois por cento) a $5 \%$ (cinco por cento) dos seus cargos com beneficiários reabilitados ou Pessoa Portadora de Deficiência, habilitados (ASSIS et al, 1994).

Há também essa obrigação de inclusão do deficiente auditivo no setor público, conforme consta na Constituição Federal de 1988: Art. 37, VIII: A lei preservará percentual de cargos e empregos públicos para as Pessoas Portadoras de Deficiência e definirá os critérios de sua admissão (ASSIS et al, 1994).

Porém, para CARREIRA (1997), apesar de existirem tantas leis, muitos empresários ainda desconhecem a capacidade de trabalho do surdo e as medidas administrativas para sua contratação (recrutamento, seleção, treinamento, legislação). 
Id on Line Revista Multidisciplinar e de Psicologia

Id on Line Multidisciplinary and Psycology Journal

\section{Língua Brasileira de Sinais - LIBRAS}

\section{Contextualização Histórica}

Nos dias de hoje, temos a Língua Brasileira de Sinais (LIBRAS) como uma língua cada vez mais reconhecida pela sociedade, na legislação, nas escolas, nas universidades, entre outros setores. Esse reconhecimento da Libras nos faz questionar: de onde veio essa língua? (DINIZ, 2010a).

Ao iniciar a pesquisa sobre mudança da Libras, podemos descrever a história da evolução da mesma no Brasil sob ordem cronológica. Nesta história da evolução da língua de sinais, relatamos que a Libras evoluiu no século XIX, através de registros históricos, podemos dizer que a LIBRAS entrou em contato com a Língua de Sinais Francesa (LSF) através do professor surdo francês E. Huet. Fundando em 1857, com o apoio do então Imperador D. Pedro II, o Instituto Imperial de Surdos-Mudos, que posteriormente passou a ser chamado de Instituto Nacional de Educação de Surdos (INES), localizado na capital do Rio de Janeiro (DE QUADROS \& KARNOPP, 2007).

Porém, em 1880 foi decidido no Congresso Internacional de Educação de Surdo, em Milão à rejeição das línguas de sinais nas escolas de surdos, focalizando apenas a língua oral. Assim foi adotado o método oral, sendo este considerado superior ao método de sinais. Em razão disso, a LIBRAS passou a ser desvalorizada e desprezada pela sociedade e a educação. Porém, isso não significa que a Libras "morreu". No INES, os alunos surdos passaram a se comunicar de forma escondida nos refeitórios e dormitórios. Em anos posteriores, a LIBRAS foi difundida pelo Brasil, já que os alunos do INES eram oriundos de outros estados brasileiros, além do Rio de Janeiro, e, quando voltavam para suas casas, levavam a língua de sinais adquirida (INES, 2007).

Por volta de década de 1980, retornou o foco da importância da Libras no ensino graças a pesquisas linguísticas e pedagógicas. Na década de 1990, em função da necessidade de melhorar a qualidade do ensino na sala de aula do INES, surgiu a profissão de monitor surdo para ser mediador na transmissão e no processo de ensino-aprendizagem entre professor ouvinte e alunos surdos (DE QUADROS \& KARNOPP, 2007). 
Id on Line Revista Multidisciplinar e de Psicologia

\section{LIBRAS}

Considerada um sistema linguístico legítimo e natural, utilizado pela comunidade surda brasileira, de modalidade gestual-visual e com estrutura gramatical independente da Língua portuguesa falada no Brasil. A LIBRAS, possibilita o desenvolvimento linguístico, social e intelectual daquele que a utiliza enquanto instrumento comunicativo, favorecendo seu acesso ao conhecimento cultural-científico, bem como a integração no grupo social ao qual pertence (DINIZ, 2010b).

As pessoas surdas consideram que por ser a LIBRAS uma língua própria da comunidade surda brasileira, deve-se procurar garantir que o ensino desta língua seja realizado, preferencialmente, por professores/instrutores surdos, viabilizando dessa forma maior riqueza interativa cultural entre professor/instrutor surdo e alunos. Diante de tal colocação, se faz necessário capacitar cada vez mais surdos para serem professores e instrutores conforme as exigências legais e o proposto pelas federações e associações de surdos. O reconhecimento oficial no Brasil da Língua Brasileira de Sinais (LIBRAS) como meio de comunicação de uso corrente, bem como a garantia pela administração pública de preparação de profissionais que atuem na área com o devido conhecimento e fluência da mesma, vêm ampliando a demanda por profissionais habilitados no ensino da Libras (LEITE, 2008).

Com a intensificação de movimentos, no início da década de 90, pela instituição da LIBRAS, como língua oficial, foi criado em 1993 um projeto de lei para a regulamentação da LIBRAS no país. Após anos de batalhas, somente no ano de 2002 a LIBRAS foi oficialmente reconhecida e aceita como segunda língua oficial brasileira, através da Lei 10.436, de 24 de abril de 2002. Mesmo com um andamento lento o progresso para a cultura Surda acontece. Em 2005, através do decreto 5.626 a LIBRAS foi regulamentada como disciplina curricular. Já em 2007, a estrutura de língua foi aplicada a LIBRAS, já que ela é uma língua natural, possui complexidades próprias e comunicação eficaz. Em 2010 foi regulamentada a profissão de Tradutor Interprete de Libras, simbolizando mais uma grande conquista. Sendo estabelecido que é dever do Poder Público garantir acesso a educação para surdos nas escolas regulares de ensino, legitimando seu aprendizado e progressão educacional (DINIZ, 2010a). 
A LIBRAS, não é apenas uma linguagem, a LIBRAS é uma língua de modalidade visual-gestual, não estabelecida através do canal oral, mas através da visão e da utilização do espaço. Como a língua de sinais se desenvolve de forma, é lógico e aceitável que os surdos se comuniquem naturalmente utilizando as mãos, cabeça e outras partes do corpo, por estarem privados da audição (CAMPELO, 2008).

Sobre isto, SALLES et al (2004, p. 24), menciona:

\begin{abstract}
A LIBRAS é adotada de uma gramática constituída a partir de elementos Constitutivos das palavras ou itens lexicais e de um léxico que se estruturam a partir de mecanismos fonológicos, morfológicos, sintáticos e semânticos que apresentam também especificidades, mas seguem também princípios básicos gerais. É adotada também de componentes pragmáticos convencionais codificados no léxico e nas estruturas da LIBRAS e de princípios pragmáticos que permitem a geração de implícitos sentidos metafóricos, ironias e outros significados não literais. A LIBRAS é a língua utilizada pelos surdos que vivem em cidades do Brasil, portanto não é uma língua universal.
\end{abstract}

A relação entre o homem e o mundo acontece mediada pela linguagem, porque permite ao ser humano planejar suas ações, estruturar seu pensamento, registrar o que conhece e comunicar-se. A língua é o principal meio de desenvolvimento do processo cognitivo do pensamento humano. Por isso a presença de uma língua é considerada fator indispensável ao desenvolvimento dos processos mentais (LEITE, 2008).

Segundo Lúria (1986), os processos de desenvolvimento da linguagem incluem o conjunto de interações entre a criança e o ambiente tornando-se necessário desenvolver alternativas que possibilitem os alunos com surdez adquirir linguagem aperfeiçoando esse potencial. Quando uma criança surda tem acesso a sua língua natural, ou seja, a língua de sinais, ela se desenvolve integralmente, pois tem inteligência semelhante a dos ouvintes, diferindo apenas na forma como aprendem que é visual e não oral-auditiva. No entanto, a maioria das crianças surdas vêm de famílias ouvintes que não dominam a língua de sinais, e por isso, é essencial a imersão escolar na primeira língua das crianças surdas, já que essa aquisição da linguagem permitem o desenvolvimento das funções cognitivas (LEITE, 2008). 
Id on Line Revista Multidisciplinar e de Psicologia

Id on Line Multidisciplinary and Psycology Journal

\section{Potencialidades educacionais dos Deficientes Auditivos}

A educação dos deficientes auditivos pode muito bem ser definida como uma história de impossibilidades. A reflexão sobre o consenso das potencialidades educacionais dos surdos não deve ser apressadamente interpretada sobre o modo como os surdos podem ser educados e como uma consequência de objetivos pedagógicos a serem desenvolvidos em termos de uma preposição metodológica (VIOTI, 2006).

As escolas dos deficientes auditivos vêm atuando de forma direta no que se refere na formação de surdos trabalhadores. Essa formação atua diretamente no que se refere à na disciplina do sujeito para uma melhor adequação às necessidades do mundo do trabalho. $\mathrm{O}$ sentido de aprendizagem possibilita ao aluno surdo uma atividade que evita que o aluno seja no futuro uma "carga" para a família. Fica evidenciado que os jovens alunos surdos vinham sendo disciplinados a uma rotina que atendia ao ritmo das antigas fábricas que surgiram na época (XAVIER, 2006).

O sentido de reabilitação pode ser facilmente encontrado em diferentes projetos direcionados às questões do trabalho nas escolas de surdos. É importante ressaltar que se a escola de surdos atende a criança e jovens que ainda não foram inseridos no mercado de trabalho, é equivocado falar em reabilitação, como se fosse necessário reparar algo ou alguém que já falhou. Essas escolhas de atividades profissionais são motivadas pela crença de muitos pais e educadores de que a informática é a atividade ideal para os surdos. Outros projetos privilegiam ofícios que não exigem escolaridade mais avançada, mas que possibilitam um trabalho mais individual, sem a necessidade de contato freqüente com o público (DINIZ, 2010a).

O compromisso assumido pelas escolas em garantir, ao seu aluno surdo uma formação para um emprego, comprovando a eficiência do processo educacional, leva as mesmas a se constituírem em agências de empregos. Alunos surdos com seus familiares vão até esses profissionais na certeza de que eles irão atender seus anseios por um emprego e pela possível independência financeira (CAMPELO, 2008).

Segundo Diniz (2010b), argumenta que surdez e problema se conectam de forma muito imediata. As dificuldades ligadas à falta de emprego resultam em um difícil acesso a informação 
Id on Line Revista Multidisciplinar e de Psicologia

Id on Line Multidisciplinary and Psycology Journal

adequada e aos processos de tomada de decisão, fazendo com que os alunos surdos e familiares procurem na escola apoio e auxilio.

\section{Metodologia}

A metodologia adotada neste trabalho foi a descritiva qualitativa, pois não teve como perspectiva a generalização dos resultados obtidos de uma amostra reduzida, mas sim, a descrição, a compreensão e a interpretação dos fenômenos observados nas entrevistas realizadas com pessoas com deficiência auditiva com vínculo formal de trabalho, no municípios de Barbalha e Juazeiro do Norte/CE. A escolha pelos municípios de Juazeiro do Norte não se deu de forma intencional, uma vez que o conglomerado formado por estas duas cidades compoe um amplo parque industrial de grande relevancia econômica.

O estudo em questão visa uma pesquisa descritiva, do tipo estudo de caso, que centrada em estudar e descrever as características, propriedades ou relações que pode haver na comunidade, grupo, ou realidade da pesquisa, com intuito de buscar diferentes concepções. Além de que o estudo de caso é composto pelas características especificas do objeto investigado, ou seja, estuda-o de forma profunda e exaustiva, pretendendo-o o conhecer de forma detalhada (GIL, 2009).

A pesquisa foi, então, realizada nas cidades de Barbalha e Juazeiro do Norte - CE, nos meses de Março e Abril de 2015. O público selecionado está na faixa etária entre 18 a 40 anos. Outro requisito considerado foi o grau de escolaridade, focando pessoas que já haviam concluído o ensino fundamental ou o médio, possibilitando assim, informações mais precisas, com maiores detalhes. Estas escolhas foram intencionais e se deve ao fato do público alvo possuírem as características específicas necessárias para a abordagem pretendida.

Para a coleta de dados, foi elaborado um questionário semi estruturado com 19 perguntas (Questionario em Anexo), dividido em tres partes: Funcionarios não ouvintes, Empregadores e Funcionarios ouvintes. Este foi elaborado com o intuito de levantar informações acerca das percepções e opiniões das pessoas sobre a inserção do deficiênte auditivo no seu mercado de 
Id on Line Revista Multidisciplinar e de Psicologia

Id on Line Multidisciplinary and Psycology Journal

trabalho. Portanto, foram realizadas entrevistas semiestruturadas apresentadas sob a forma de roteiro preliminar de perguntas, que se moldou à situação concreta dos entrevistados.

As instituições selecionadas estão inseridas em diferentes segmentos, mas para resguardar o sigilo das mesmas, foi atribuido a seguinte denominação:

Intituição A - Industria

Instituição B - Industria e Comercio

Instituição C - Educação

Tabela 01 - Amostragem de Funcionario Entrevistados

\begin{tabular}{lcccc}
\hline & $\begin{array}{c}\text { Funcionario Ouvintes } \\
\text { / Entrevistados }\end{array}$ & $\begin{array}{c}\text { Empregadores / } \\
\text { Entrevistados }\end{array}$ & $\begin{array}{c}\text { Deficientes Auditivos } \\
\text { / Entrevistados }\end{array}$ & TOTAL \\
\hline Intituição A & $155 / 15$ & $15 / 8$ & $10 / 10$ & 180 \\
Instituição B & $250 / 25$ & $20 / 10$ & $10 / 10$ & 280 \\
Instituição C & $82 / 8$ & $8 / 4$ & $12 / 12$ & 102 \\
\hline
\end{tabular}

Fonte: Pesquisa (Barbalha e Juazeiro do Norte, Ceará, 2015).

Foram entrevistados quantidades variadas de pessoas em cada instituição, tal fato ocorreu em virtude da diferença no numero de funcionarios de cada uma delas, mas respeitando sempre o mesmo percentual de $10 \%$ dos funcionarios ouvintes, $50 \%$ Chefes e empregadores, $100 \%$ dos funcionarios com deficiencia auditiva. A Tabela 01, tras os quantitativos de funcionarios de cada um dos grupos estudos, a seleção Assim a amostragem em cada das instituições ficou da seguinte forma:

\section{Resultados e Discussão dos Dados}

A Pesquisa foi realizada em tres empresas com diferentes ramos de negocios, distribuidas nas cidades de Barbalha e Juazeiro do Norte - CE. Dividiremos os resultados em 
tres partes, na primeira apresentaremos alguns dados estatisticos coletados, na segunda parte faremos uma analise individualizada sobre os dados obtidos em cada uma das intituições. Na terceira parte traçaremos um perfil com base na realização das entrevistas de cada um dos agentes entrevistados com os empregadores, funcionarios ouvintes e funcionarios com deficiencia auditiva.

\section{Análise dos Dados}

\section{Quadro Funcional}

Antes de iniciar o processo de entrevistas foi realizado um levantamento a respeeito do quadro funcional das instituições estudadas, os dados obtidos estão expostos no Grafico 03.

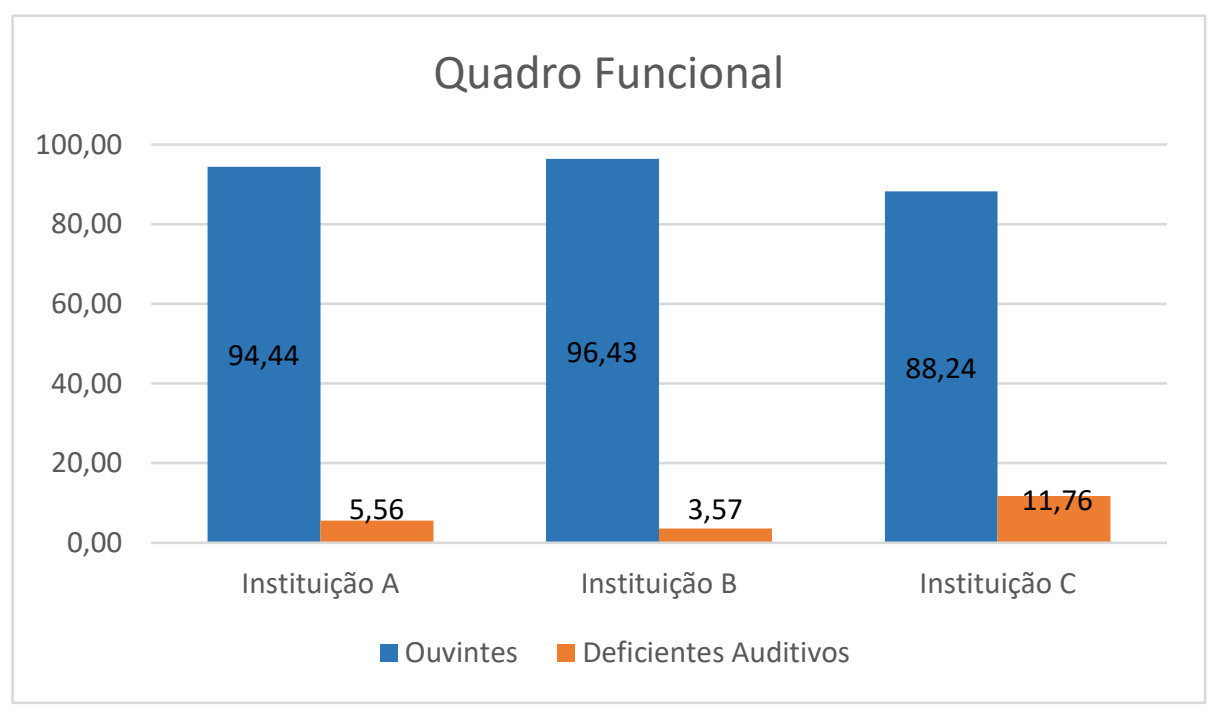

Grafico 03: Quadro Funcional

Com base nas insformações expostas acima, podemos identificar que todas as instituições estudas, possuem em seu quadro funcional um quantitativo de funcionários superior 
ao que estabelece a Lei $N^{o} 8.213 / 91$. Esta lei estipula que empresas com quadro funcional de ate 500 funcionários deve possuir 3\% das vagas destinadas a pessoas com deficiência. Dessa forma, podemos evidenciar que as empresas atendem ao que estabelece a legislação. E importante salientar que os valores expostos no Gráfico 03, considera apenas o número de funcionários com deficiência auditiva, tal fato demostra que se tivéssemos considerados pessoas com qualquer tipo de deficiência, o número de contratações das instituições estudas seria ainda maior ao que estabelece a lei.

\section{Gênero}

Em toda pesquisa cientifica baseada na coleta de dados mediante realização de entrevistas, se faz necessario a classificação dos entrevistados em relação ao seu genero, tais dados são apresentados a seguir no Grafico 04.

\section{Gênero}

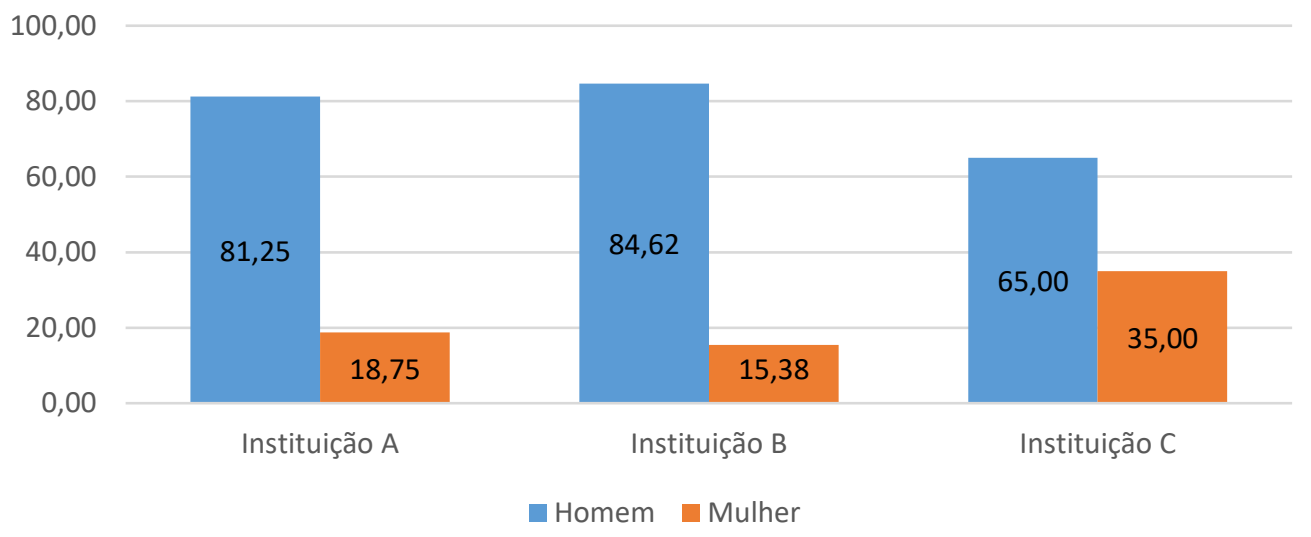

Grafico 04: Gênero

No Cenario exposto no Grafico 04, podemos identificar que o quadro funcional das empresas estudas e composto em sua grande maioria por homens, tal fato impossibilitou a 
realização de uma amostragem mais uniforme em relação ao genero. É importante salientar que apenas a Instituição $\mathrm{C}$, possui em quadro funcional mulheres com defieciencia auditiva. As demais Instituições não possuem mulheres com deficiencia auditiva em seu quadro funcional. Segundo os empregadores a contratação de mulheres não ocorre em virtude da falta de mão de obra qualificada.

\section{Conhecimento sobre LIBRAS}

Saber se o Deficiente Auditivo tem dominio sobre a LIBRAS, configura algo de extrema importancia, porem quando este surdo está inserido no ambiente de trabalho o conhecimento de LIBRAS pelos demais funcionarios passa a tambem ser importante no processo de inclusão social. O Grafico 05, tras um compartivo dos dados encontrados em cada uma das Instituições estudadas.

\section{Conhecimento de LIBRAS}

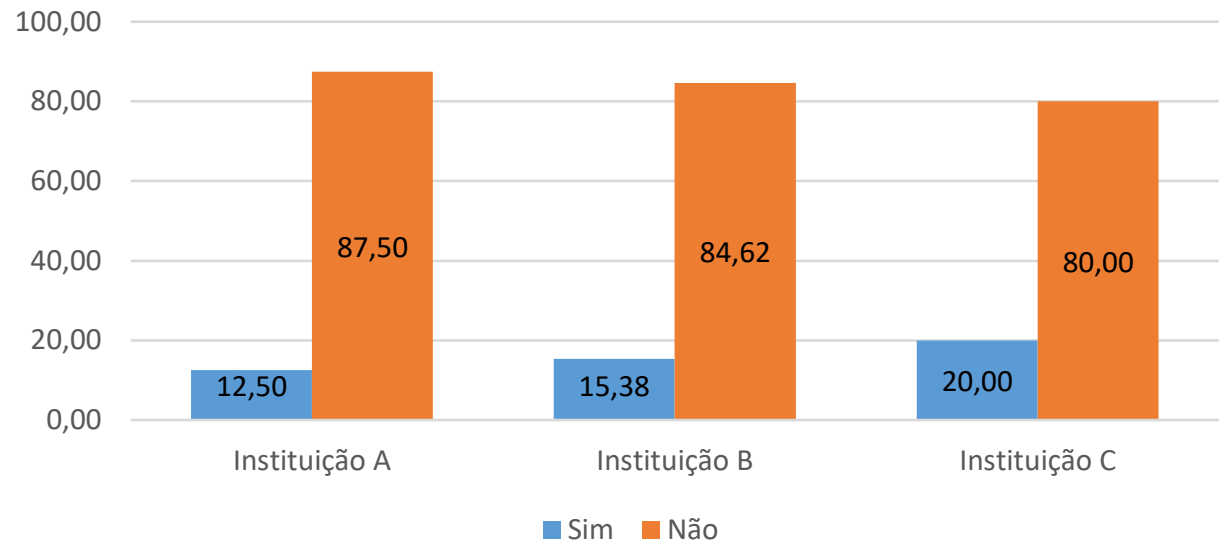

Grafico 05: Conhecimento de LIBRAS

Com base nos dados acima, fica evidente que o conhecimento sobre LIBRAS e um item ainda raro, fora da Comunidade Surda. O cenario encontrado nas instituições é praticamente igual, porem aquela que apresentou melhores resultados foi a instituição $\mathrm{C}$, atribuimos tal 
cenario, ao fato de que a instuição $\mathrm{C}$, desempenha uma serie de atividades educacional e de atendimento ao publico, assim a utilização da LIBRAS atua como peça fundamental no cotidiano de trabalho dos servidores dessa intituição. Nas outras instituições a utilização da LIBRAS, seria apenas em processos de interação interna, porem a interação dos deficientes auditivos com os trabalhadores ouvintes, ainda não vem recebendo a devida atenção por parte dos empregadores.

\section{Análise dos Agentes Entrevistados}

A seguir descreveremos os relatos obtidos aparti das entrevistas com cada um dos agentes envolvidos no processo de interação do deficiente auditivo com o ambiente de trabalho.

\section{Empregadores}

Inicialmente foi solicitado aos empregadores que avaliasse o desempenho dos funcionários com deficiência auditiva (Grafico 06).

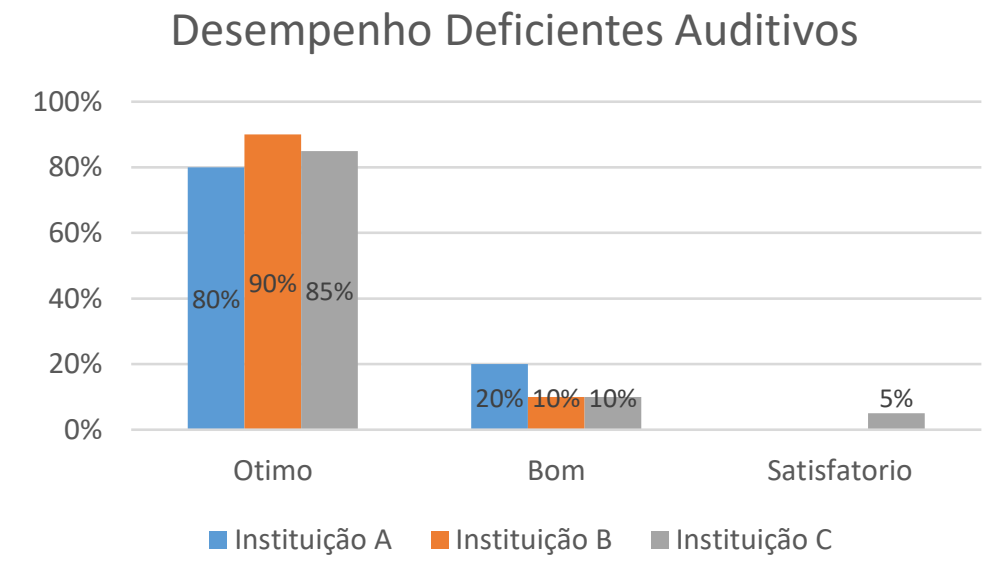

Grafico 06: Avaliação Desempenho Profissional 
Os resultados obtidos para esse questionamento mostram grande semlhança, uma vez que em todas as instituições os entrevistados responderam que os deficientes auditivos são funcionários muito competentes no que fazem, que aprendem rápido a função, possuem grande interesse em aprender coisas novas. Possuem elevada atenção e não dispersam facilmente sua atenção da atividade realizada, uma vez que os ruídos não tiram sua atenção. No Grafico 07, demostra os dados sobre como os empregadores avaliam o nivel de interação e sua relação com ou funcionarios não ouvintes. A grande parte dos entrevistados disseram que a relação e boa, mal a comunicação precaria atua como agente limitador, fato percebido quando observamos os dados expostos abaixo. Quanto a este quesito a Instituição B, apresentou os piores resultados. Assim percebemos que embora haja muito respeito entre ambos, o processo de inclusão ainda deixa muito a desejar.

\section{Relacão Deficientes Auditivos}

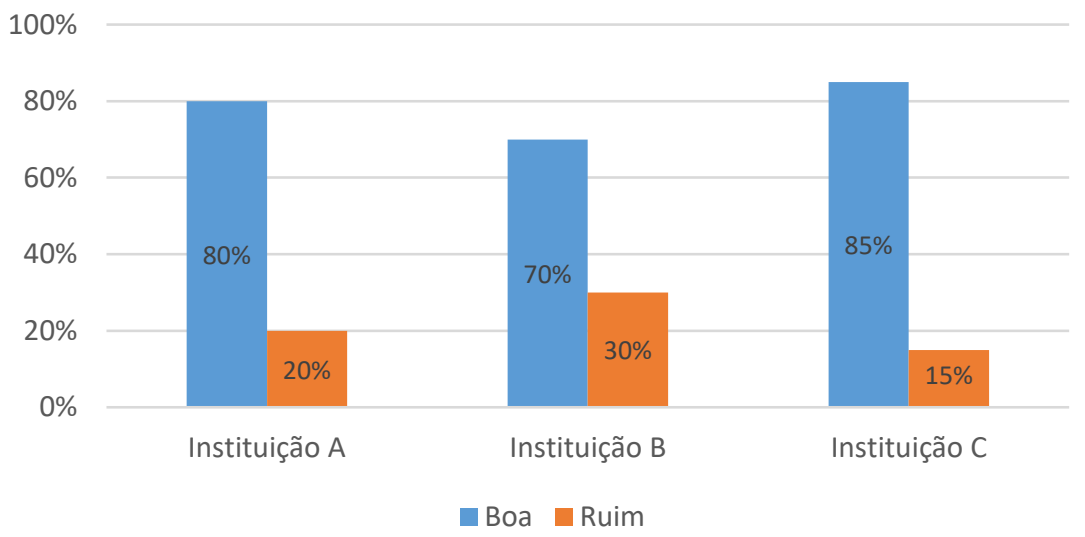

Grafico 07: Avaliação Relacionamento

\section{Funcionário Ouvinte}

Em relação as entrevistas realizadas com os funcionários ouvintes em sua grande maioria foi declarado que eles não são preparados para trabalharem com deficientes auditivos, 
fato que acarreta grande dificuldade para haja uma maior interação, como pode ser observado no Grafico 08.

\section{Relacão Deficientes Auditivos}

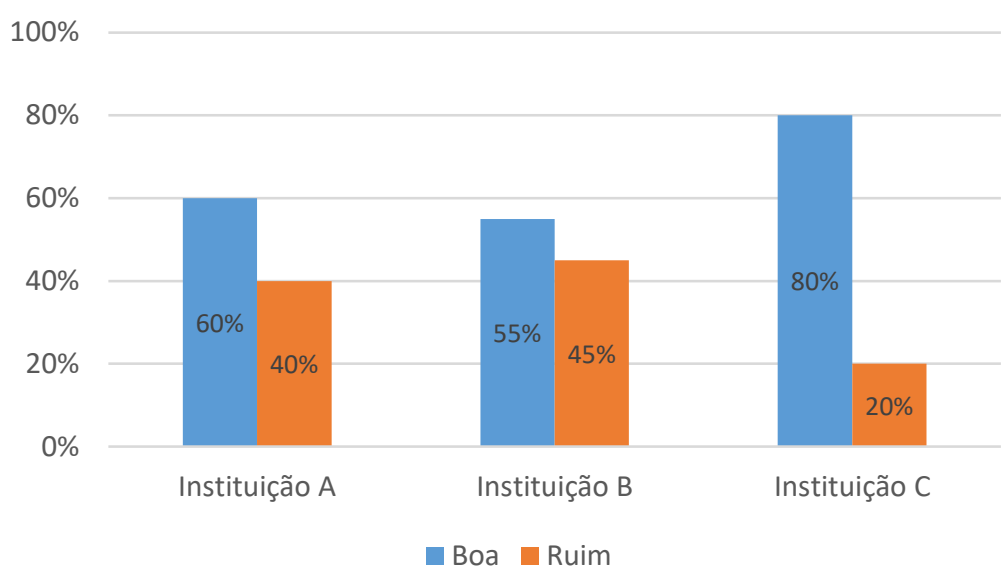

Grafico 08: Avaliação Relacionamento

Podemos observar que as Instituições A e B, apresentaram resultados similares. A Instituição C, apresentou os melhores indicadores de relação, atribuimos tal caracteristicas ao fato comunicação, uma vez que nessa instituição existe um numero maior de funcionarios ouvintes com conhecimentos sobre LIBRAS. Um fato comum nas Instituições A e B e que quando os funcionarios ouvintes precisam pedir algum favor aos não ouvintes, estes não sabem como fazer, segundo eles também e muito comum os funcionários ouvintes tentarem falar com o deficiente auditivo, por não saberem ou lembrarem de sua condição. Nos relatos percebemos também que alguns funcionários ouvintes gostam da amizade dos deficientes auditivos e acham que os donos das empresas devem repensar a forma com está acontecendo o relacionamento entre eles, para que não só a forma de comunicação venha melhorar, como também o desenvolvimento do trabalho. Alguns inclusive surgeriram a necessidade das instituições oferecerem curso de LIBRAS para os funcionários com objetivo de melhorar a comunicação interna. 
Id on Line Revista Multidisciplinar e de Psicologia

Id on Line Multidisciplinary and Psycology Journal

\section{Funcionário Deficiente Auditivo}

O primeiro questionamento proposto repostava ao nivel de escolaridade dos entrevistados, podemos observar no Grafico 09, que as instituições apresentam resultados diferentes. Na Instituição A, observamos que a grande maioria do funcionarios com deficiencia auditiva possuem qualificação tecnica, fato atribuido a necessidade de utilização de mão de obra qualificada, segundo relatos muitos receberam treinamento após ingressarem na instituição. Na instituição B, embora a grande maioria seja de funcionarios com qualificação tecnica, tambem existe um grande parcela de funcionarios com apenas o ensino medio. A instituição $\mathrm{C}$ apresenta em seu quandro funcional deficientes auditivos com nivel superior, tal fato ocorreu em virtude dessa ser uma instituição de ensino, havendo a necessidade de uma maior qualificação de seus funcionarios.

\section{Escolaridade Deficientes Auditivos}

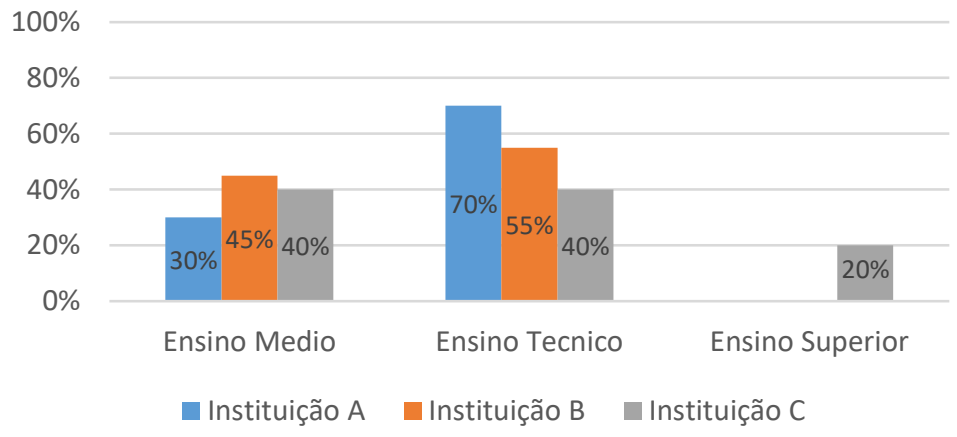

Grafico 09: Nivel Escolaridade

A seguir no Grafico 10 apresentaremos os dados referente a como os funcionarios não ouvintes avaliam seu relacionamento com os funcionario ouvintes, questionando se estes sentiase isolado na empresa, a grande maioria falou que não, que sempre está com uma pessoa por perto, mesmo que esta não saiba LIBRAS, mais com gestos ele entende e tenta fazer com o que 
o ouvinte o entenda também, para que haja um melhor relacionamento entre eles. Podemos observar que nesse indicador as instituições se assemelham.

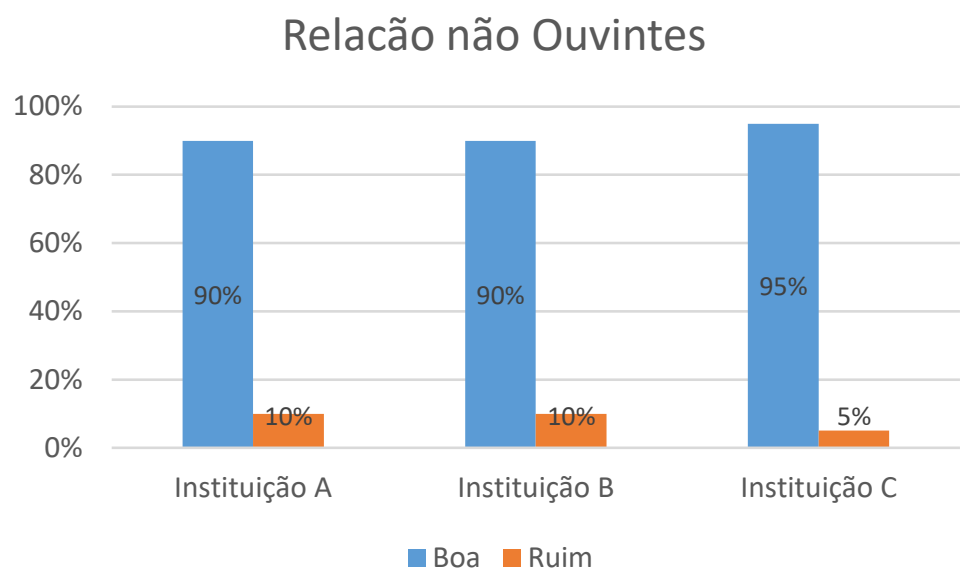

Grafico 10: Avaliação Relacionamento

Ao longo das entrevistas podemos observar que a interação dos deficientes auditivos com os demais funcionarios ocorre com bastante facilidade. Mas ficou evidente que embora haja comunicação com os funcionários ouvintes esta ainda acontece com dificuldade porque a maioria não sabe LIBRAS, e os poucos aqueles que sabem, ainda não dominam a língua.

Após estes questionamentos identificamos que o principal agente limitador da vivência dos surdos no âmbito do trabalho é à precária comunicação no ambiente de trabalho, motivada pela falta de conhecimento da LIBRAS. Foi relatado pelos entrevistados que de todas as instituições que estas não possuem o intérprete da LIBRAS, salvo em ocasiões excepcionais. Ressalta-se que todos os os deficientes auditivos entrevistados possuem conhecimento da LIBRAS e afirmam que a presença deste profissional nas empresas é de extrema importância para que a comunicação seja mais eficaz entre a instituição, colegas de trabalho ouvintes e os funcionários com deficiência auditiva.

No que tange a faixa salarial, não foi identificado distinção salarial entre os funcionarios ouvintes e os deficientes auditivos, quando este exercem a mesma função. A grande maioria 
Id on Line Revista Multidisciplinar e de Psicologia

Id on Line Multidisciplinary and Psycology Journal

dos funcionarios com deficiencia auditiva exerce funções com uma faixa salarial que varia de 1 a 2 salarios mininos, sendo esta a faixa aplicada pela grande maioria das empresas instaladas em nossa região. Mas no que diz respeito ao crescimento profissional, foi constatado que a os deficientes auditivos em sua grande maioria não possuem a perspectiva de ascensão na empresa. Mas e importante ressaltar que em geral as empresas de nossa região não possuem uma política de promoções muito eficiente.

\section{Considerações Finais}

Com base nas informações citadas acima, podemos observar diferentes niveis de interação entre os funcionarios ouvintes e os não ouvintes nas tres instituições. Mas alguma caracteristicas entre elas se assemelham. Nenhuma delas possui em seu quadro funcional a presença de um interprete, tal fato atua como agente limitador da interação entre os funcionarios. Outro fator comum e que o processo de inclusão com os demais funcionarios, limita-se a apenas à apresentação dos setores e de alguns funcionarios, isso demonstra uma falha no processo de inclusão, ficando evidenciado quando identificamos que a interação dos deficientes auditivos ocorre apenas com os funcionarios ouvintes locados no mesmo setor.

Identifica-se que a prática da inclusão social e o ingresso no mercado de trabalho, das pessoas com deficiência auditiva, é algo ainda muito recente no Brasil. Apesar disso nos últimos anos, vem sendo realizados vários estudos sobre essa temática de inclusão de pessoas com deficiência auditiva em diferentes âmbitos, embora o entendimento dessa problemática ainda se encontra em processo de construção.

É importante ressaltar que nas ultimas décadas no Brasil ocorreram inúmeros avanços legislativos. Portanto, atualmente, o maior problema que enfrenta a pessoa com deficiência auditiva não é a ausência de leis, mas sim, a aplicabilidade destas leis, uma vez que, como foi constatado nesta pesquisa a inclusão da pessoa com deficiência no mercado de trabalho, apesar de prevista em lei, normalmente não é contemplada na política interna de recursos humanos das empresas, tal fato fica evidente quando analisamos os dados apresentados no grafico 03, onde 
Id on Line Revista Multidisciplinar e de Psicologia

Id on Line Multidisciplinary and Psycology Journal

são apresentados os dados referente ao conhecimento sobre LIBRAS, fica evidente que não há por parte dos empregadores preocupação com o processo de inclusão e interação dos servidores com deficiencia auditiva com os demais servidores.

Nesse contexto destaca-se o fato das empresas precisarem mudar sua cultura se tornando o local de trabalho igual para todos, procurando oferecer métodos que facilitem a comunicação entre os funcionários com deficiência auditiva e os funcionários ouvintes. É importante que a sociedade compreenda as pessoas com deficiência auditiva como seres humanos capazes e que detem habilidades. Podendo assim vencer, produzir e trabalhar do mesmo modo que os ouvintes trabalham.

Ainda faz-se necessário perceber, que o trabalho para a pessoa com deficiência auditiva tem um cunho significativo, ao que se refere à sua inclusão na sociedade. Podemos identificar que o convívio no ambiente de trabalho proporciona uma elevação da autoestima e um sentimento de aceitação. Assim, a inclusão da pessoa com deficiência auditiva no mercado de trabalho não deve se restringir à aplicação de leis e de projetos de responsabilidade social por parte das empresas.

Com base nas informações descritas nesse trabalho, concluirmos que a pesquisa conseguiu alcançar os objetivos propostos, uma vez que a interpretação dos dados, foi possivel identificar que pessoa com deficiencia já esteja inserida no mercado de trabalho da região do Cariri. Mas podemos identificar que existe uma serie de limitações na inclusão do individuo com deficiencia, tais limitações vão desde questões de infraestrutura fisica das instituições e dificuldades de relacionamento com os demais funcionarios, ocasionado principalmente pela falta de conhecimento sobre LIBRAS. Podemos destacar como ponto positivo o fato termos recebido total apoio por parte das instituições, ao longo da pesquisa não houve qualquer obstaculo adminitrativo e nem por parte dos funcionarios.

Assim podemos concluir que apesar de existirem pesquisas sobre o tema o trabalho trouxe o olhar para a realidade do surdo no mercado de trabalho da região do Cariri, não com a intenção de esgotar o tema, mas pontecializar novas discussões sobre o mesmo. 
Id on Line Revista Multidisciplinar e de Psicologia

Id on Line Multidisciplinary and Psycology Journal

\section{Referências}

ASSIS, O. Q. et al. Os direitos da pessoa portadora de deficiência. São Paulo: Lúmen, 1994. p. 56-69.

BATISTA, C. A. M. et al. Inclusão dá trabalho. Belo Horizonte: Armazém de idéias, 2000.

BATISTA, C. A. M. Inclusão: construção na diversidade. Belo Horizonte: Armazém de Idéias, 2004.

BRASIL. Constituição; República Federativa do Brasil. Brasília: Senado Federal, Centro Gráfico,1988.

CAMPELlO, A. R. S. Origens da língua de sinais brasileira. Comunicação. Semana de Letras. Centro de Comunicação e Expressão. UFSC: Florianópolis. 2008.

CARREIRA, D. A integração da pessoa deficiente no mercado de trabalho. In M. T. E. Mantoan (Org.). Integração de pessoas com deficiência: contribuições para a reflexão sobre o tema. São Paulo: Memnon. (1997).

CORRÊA, M. E. V. Reflexões Sobre a Inclusão do Aluno com Deficiência Auditiva. 2009.

DA SILVA FÉliX, A. E. A. et al. A Inclusão da Pessoa Surda da Comunidade Escolar: 2010.

DE QUADROS, R. M. \& KARNOPP, L. B. Língua de sinais brasileira: estudos lingüísticos. Artmed, 2007.

DÍAZ, F. et al. Educação inclusiva, deficiência e contexto social: Questões contemporâneas. EDUFBA, 2009.

DINIZ, H. G. et al. A História da Língua de Sinais Brasileira (Libras): um estudo descritivo de mudanças fonológicas e lexicais. 2010b.

DINIZ, H. G. et al. A História da Língua de Sinais Brasileira (Libras). 2010a.

DOS SANTOS, L. A. R. O deficiente auditivo: dispositivos legais e a difícil trajetória no mundo do trabalho. Revista Jurídica On-line, v. 1, n. 2, 2014.

FENEIS, Federação Nacional de Educação e Integração dos Surdos. Disponível em: $<$ http://www.feneis.com.br/page/index.asp $>$ Acesso em 17/03/2015.

GIL, A. C. Métodos e Técnicas de Pesquisa Social. 6. ed. São Paulo: Atlas, 2009. 
Id on Line Revista Multidisciplinar e de Psicologia

Id on Line Multidisciplinary and Psycology Journal

GIL, M. O que as empresas podem fazer pela inclusão de pessoas com deficiência. São Paulo: Instituto Ethos, 2002.

GURGEL, M. A. Pessoas com deficiência e o direito ao trabalho. Florianópolis: Obra Jurídica, 2007.

IBGE, Instituto Brasileiro de Geografia e Estatística. Censo 2010.

INES, O Instituto Nacional de Educação de Surdos/INES e a Educação de Surdos no Brasil - Aspectos da trajetória do Instituto Nacional de Educação de Surdos em seu percurso de 150 anos. v.01, dez/07. Rio de Janeiro: INES. 2007.

IPECE, Instituto de Pesquisa e Estratégia Econômica do Ceará. Panorama das Pessoas Portadoras de Alguma Deficiência no Ceará, Fortaleza, 2012. Disponível em < http://www.ipece.ce.gov.br/publicacoes/EnfoqueEconomicoN23_27_02_2012.pdf> . Acesso em 24 de Março de 2015.

KLEIN, M.. Os discursos sobre surdez, trabalho e educação e a formação do surdo trabalhador. A surdez: um olhar sobre as diferenças. Porto Alegre: Mediação, p. 75-93, 1998.

LEITE, T. A. A segmentação da Língua de Sinais Brasileira (Libras): Um estudo linguístico descritivo a partir da conversação espontânea entre surdos. Tese de doutorado. São Paulo: USP. 2007.

LURIA, A. R. Pensamento e linguagem: as últimas conferências de Luria. Artes Médicas, 1986.

MAZZOTTA, M. J. S. Educação especial no Brasil: história e políticas públicas. 4. ed. São Paulo: Cortez, 2003.

PAIVA, A. P. et al. A Inclusão do Surdo no Mercado de Trabalho. 2013.

PINTO, B. D. et al. Inclusão e Permanência da Pessoa Surda no Mercado Formal de Trabalho. 2009.

RAIS, Relação Anual de Informações Sociais. Características do Emprego Formal segundo a RAIS; 2010. Disponivel em <http://www. mte. gov. r/rais/2010/arquivos/Result_Definitivo.pdf> Acesso em 20 de Março de 2015.

SALlES, H. M. M. L. et al. Ensino de Língua Portuguesa para Surdos, vol. 1 - caminhos para a pratica pedagógica, Programa Nacional de Apoio à Educação dos Surdos, 2004.

SASSAKI, R. K. Inclusão - Construindo uma sociedade para todos. 7. Ed. Rio de Janeiro: WVA, 2006. 
SASSAKI, R. K. Inclusão: construindo uma sociedade para todos. 1. ed. Rio de Janeiro: WVA, 1997. SILVA, O. M. da. A epopéia Ignorada: A pessoa deficiente na história do mundo de ontem de hoje. São Paulo: CEDAS, 1987.

SILVEIRA, F. F. R. As representações sociais dos surdos e a construção das suas identidades. 2009. Tese (Doutorado em Psicologia Social, do Trabalho e das Organizações) Universidade de Brasília, Brasília, 2009.

SOUSA, W. P. de A. A Inclusão da Pessoa Surda: Especificidades no Âmbito Educacional. 2010.

TELES, H. F. R. A Aceitação do Deficiênte Auditivo no Mercado de Trabalho. 2011.

VIOTTI, E. Introdução aos Estudos Linguísticos. Curso de Letras/Libras - UFSC. 2006.

XAVIER, A. N. Descrição fonético-fonológica dos sinais da Língua de Sinais Brasileira (LSB/Libras). Dissertação de mestrado em Linguística. Faculdade de Filosofia, Letras e Ciências Humanas (FFLCH)- USP. 2006.

Como citar este artigo (Formato ABNT):

FREITAS, Geovane R.; MARANHÃO, Thercia L. G.; FÉLIX, Waleska M. A Deficiência Auditiva e a possibilidade de Inclusão no Mercado de Trabalho. Id on Line Revista Multidisciplinar e de Psicologia, Fevereiro de 2017, vol.11, n.34, p. 185-218. ISSN: 1981-1179.

Recebido: 06.02.2017

Aceito: 27.02.2017 